\title{
Pemberdayaan Petani Kopi Karo melalui Pengolahan Pasca Panen
}

\author{
Anita Christine Sembiring*1, Delima Sitanggang, Nina Purnasari Sinuhaji \\ ${ }^{1}$ Universitas Prima Indonesia \\ ${ }^{1}$ Fakultas Teknologi dan Ilmu Komputer \\ ${ }^{2}$ Fakultas Ekonomi \\ e-mail: *anitakembaren@unprimdn.ac.id
}

\begin{abstract}
Abstrak
Pengolahan pasca panen yang baik dan benar akan memberikan dampak yang baik bagi kualitas sebuah tanaman. Demikian pula buah kopi bila budidaya tepat dan proses pengolahan pasca panen tepat dan benar maka kualitas kopi akan baik. Melihat permintaan pasar yang tinggi akan kopi Indonesia dan khususnya kopi daerah karo maka petani kopi karo harus menambah informasi dan pengetahuannya akan proses pasca panen buah kopi, petani kopi harus berbenah dan melakukan perbaikan. Petani Kopi Karo yang berada di Desa Lingga Tanah Karo merupakan mitra dari tim PKM Universitas Prima Indonesia. Mitra memiliki kendala seperti keterbatasan pengetahuan, keterbatasan alat dan teknologi dalam pengolahan pasca panen, dan pemasaran produk. Dengan pendampingan dan pendidikan yang diberikan maka permasalahan mitra dapat dipecahkan bersama. Meningkatnya pengetahuan petani dalam tahapan pemahaman tentang budidaya kopi, pengolahan pasca panen kopi sangat berperan penting dalam menentukan kualitas dan cita rasa kopi. Dengan edukasi dan monitoring yang tetap dilakukan maka petani menjadi paham tahapan proses pengolahan pasca panen. Dengan dukungan Hibah DRPM Kemenristekdikti skema Program Kemitraan Masyarakat (PKM) melakukan pendampingan dan pendidikan bagi petani kopi karo di desa lingga dengan memberikan bantuan alat kupas kulit tanduk (huller) agar petani dapat memproses lebih lanjut memproses hasil kebun mereka dimana selama ini dijual dalam bentuk gabah kemudian dapat dijual dalam bentuk green bean.
\end{abstract}

Kata Kunci : Kopi Karo, Pemberdayaan Petani, Pengabdian Kemitraan Masyarakat

\begin{abstract}
Good post-harvest processing will give a good impact on the quality of a plant. Likewise, if the coffee is right and the post-harvest processing is right and right, the quality of the coffee will be good. Seeing the high market demand for Indonesian coffee and especially Karo regional coffee, Karo coffee farmers must add information and knowledge to the post-harvest process of coffee fruit, coffee farmers must improve and make improvements. Karo Coffee Farmers who are in the Village Lingga Tanah Karo are partners of the PKM team Universitas Prima Indonesia. Partners have constraints such as limited knowledge, limited tools and technology in post-harvest processing, and product marketing. With the assistance and education provided, partner problems can be solved together. Increased knowledge of farmers in the stages of understanding about coffee cultivation, post-harvest processing of coffee is very important in determining the quality and taste of coffee. By continuing education and monitoring, farmers will understand the stages of post-harvest processing. With the support of the Ministry of Research and Technology DRPM Grant, the Community Partnership Program (PKM) scheme provides assistance and education for karo coffee farmers in the village of lingga by providing assistance with a huller peel so that farmers can further process their garden products which have been sold as grain. Then it can be sold as a green bean.
\end{abstract}

Keywords - Karo Coffee, Farmer Empowerment, PKM 


\section{PENDAHULUAN}

Pengolahan pasca panen yang baik dan benar akan memberikan dampak yang baik bagi kualitas sebuah tanaman. Tanaman komoditas kopi juga harus di budidaya dengan tepat. Dalam proses pengolahan pasca panen yang tepat dan benar akan menghasilkan kualitas kopi yang baik. Kopi dikenal luas sebagai minuman dengan cita rasa khas dan dipercaya mempunyai manfaat besar bagi peminumnya. Biji kopi yang siap diperdagangkan adalah berupa biji kopi kering yang sudah terlepas dari daging buah, kulit tanduk dan kulit arinya, butiran biji kopi yang demikian ini disebut kopi beras (coffca beans). Kopi beras berasal dari buah kopi basah yang telah mengalami beberapa tingkat proses pengolahan.

Kopi merupakan salah satu hasil komoditi perkebunan yang memiliki nilai ekonomis yang cukup tinggi di antara tanaman perkebunan lainnya dan berperan penting sebagai sumber devisa negara. Kopi tidak hanya berperan penting sebagai sumber devisa melainkan juga merupakan sumber penghasilan bagi tidak kurang dari satu setengah juta jiwa petani kopi di Indonesia [1]. Teknologi budi daya dan pengolahan kopi meliputi pemilihan bahan tanam kopi unggul, pemeliharaan, pemangkasan tanaman dan pemberian penaung, pengendalian hama dan gulma, pemupukan yang seimbang, pemanenan, serta pengolahan kopi pasca panen. Pengolahan kopi sangat berperan penting dalam menentukan kualitas dan cita rasa kopi.

Saat ini, peningkatan produksi kopi di Indonesia masih terhambat oleh rendahnya mutu biji kopi yang dihasilkan sehingga mempengaruhi pengembangan produksi akhir kopi. Hal ini disebabkan, karena penanganan pasca panen yang tidak tepat antara lain proses fermentasi, pencucian, sortasi, pengeringan, dan penyangraian. Selain itu spesifikasi alat/mesin yang digunakan juga dapat mempengaruhi setiap tahapan pengolahan biji kopi. Oleh karena itu, untuk memperoleh biji kopi yang bermutu baik maka diperlukan penanganan pasca panen yang tepat dengan melakukan setiap tahapan secara benar.

\section{TUJUAN DAN MANFAAT}

\subsection{Tujuan dan Manfaat}

Tujuan dari kegiatan Pengabdian kepada Masyarakat ini menjawab permasalahan mitra yang ada yaitu:
1. Meningkatkan kapasitas petani kopi desa Lingga dalam pengelolaan hasil alam, yaitu kopi

2. Masyarakat diharapkan dapat lebih produktif untuk mengelola hasil pertanian kopi khususnya pengolahan pasca panen.

Dan diharapkan setelah pengabdian kepada masyarakat dilaksanakan masalah yang selama ini dirasakan oleh para petani dalam informasi tentang pengolahan pasca panen dan pemasaran hasil kopi dapat diselesaikan.

\subsection{Permasalahan Mitra}

Melalui diskusi dan observasi ke lapangan, beberapa data dan hasil yang menjadi permasalahan mitra dapat dikategorikan sebagai berikut :

1. Minimnya pengetahuan pengolahan pasca panen biji kopi

2. Keterbatasan penggunaan Teknologi dalam pengolahan pasca panen

3. Keterbatasan Peralatan pengolahan

4. Keterbatasan Pemasaran

\section{Metode Pelaksanaan PKM}

Metode yang digunakan dalam kegiatan PKM adalah dengan melakukan kegiatan pelatihan yang diawali terlebih dahulu dengan pemberian materi, kemudian diskusi, praktik atau simulasi dan pendampingan. Kegiatan pelatihan dipandu oleh narasumber (tenaga ahli) sebagai fasilitator pelatihan dan dibantu dengan pemberian alat yaitu mesin huller untuk melakukan pemisahan biji kopi dari cangkangnya. Adapun tahapan dalam kegiatan PKM diantaranya adalah persiapan kegiatan PKM dengan diskusi dengan kepala desa, Melakukan Focus Grup Discussion (FGD), Pelaksanaan Pelatihan, dan Monitoring dan Evaluasi.

\section{1) Persiapan dan Pembekalan}

Tahap persiapan dilakukan beberapa kegiatan, yaitu : a. Survei tempat pelaksanaan kegiatan, dalam hal ini mitra PKM adalah petani kopi di desa Lingga, Kecamatan Simpang Empat,Kabupaten Karo.

b. Wawancara dilakukan dengan Kepala Desa yaitu Bapak Serpis Ginting bertujuan untuk mendapatkan keterangan langsung kondisi perekonomian masyarakat, kondisi petani kopi di Desa Lingga, tantangan dan peluang serta kebutuhan yang akan dipenuhi.

c. Penyusunan jadwal kegiatan. Penyusunan jadwal tersebut dimaksudkan agar pelaksanaan kegiatan terlaksana dengan teratur dan terarah. 
d. Penyusunan materi dan modul pelatihan/pendampingan. Materi PKM disusun dalam bentuk modul dengan tujuan agar penyampaian materi dapat terarah dan terdokumentasi.

\section{2) Sosialisasi}

Sebelum melakukan pelaksanaan kegiatan maka tim PKM UNPRI akan melakukan sosialisasi kepada petani yang ada di Desa Lingga, Kabupaten Karo akan tujuan dari PKM ini. Hal ini juga merupakan sarana Focus Discussion Group (FGD) mendengarkan saran dan masukan dari petani dan perangkat desa.

\section{3) Pelaksanaan Kegiatan}

Pelaksanaan kegiatan dibagi menjadi beberapa tahap, yaitu :

1. Pendampingan dan pelatihan proses pasca panen kopi yang baik

2. Mendatangkan narasumber untuk memberikan pencerahan dan penjelasan dalam pengolahan kopi pasca panen

3. Pengadaan alat-alat pengolahan pasca panen yang dibutuhkan kelompok tani.

Kegiatan pelatihan ini menguraikan materi meliputi pengolahan kopi pasca panen yang standard sehingga menghasilkan kopi yang berkualitas. Pelatihan ini akan menggunakan metode pendidikan orang dewasa dengan prinsip belajar dari pengalaman. Prinsip inilah yang menjadi landasan pendekatan seluruh proses pelatihan dimana peserta menjadi pelaku utama dalam pencapaian tujuan pelatihan.

Peserta berpartisipasi aktif dalam kegiatan dengan menjalani setiap tahapan kegiatan dengan baik dan antusias ditinjau dari banyaknya peserta yang terlibat dalam kegiatan praktik dan tanya jawab. Materi yang diberikan dalam kegiatan ini sudah sesuai dengan Term of Reference (TOR) kegiatan yang diajukan kepada pemateri. Sebelumnya, penyusunan TOR sendiri disesuaikan dengan hasil assessment yang dilakukan untuk mengetahui apa materi yang dibutuhkan oleh petani kopi di desa lingga. Respon yang diberikan oleh peserta juga cukup bagus, terlihat dari cukup aktifnya peserta dalam tanya jawab dengan pemateri. Berdasarkan hasil jawaban petani, maka dapat ditinjau bahwa peserta mengalami perubahan yang positif dengan meningkatkan pengetahuan akan pengolahan kopi pasca panen untuk mendapatkan nilai-nilai ekonomis dari pengelolaannya.

\section{4) Evaluasi Program}

Tahapan ini dilakukan untuk mengetahui tingkat keberhasilan kegiatan, sehingga dapat dilakukan penyempurnaan apabila ditemui kekurangan- kekurangan selama kegiatan pelatihan dan pendampingan dilaksanakan. Evaluasi dilaksanakan pada awal kegiatan, saat kegiatan berlangsung dan pada akhir kegiatan. Evaluasi dilakukan dengan beberapa metode yaitu dengan pengamatan langsung dan kuisioner. Kuisioner dimaksudkan untuk mengetahui pendapat dari kelompok petani mengenai kegiatan ini, sehingga dapat diketahui apakah tujuan dari kegiatan ini sudah tercapai atau belum.

\section{HASIL DAN PEMBAHASAN}

\section{1) Persiapan dan Pembekalan}

Pada Tahapan Persiapan, Tim mengunjungi lokasi dan bertemu dengan Kepala Desa Lingga dan Ketua Kelompok Tani Kopi yang menjadi mitra sasaran Pengabdian Masyarakat.

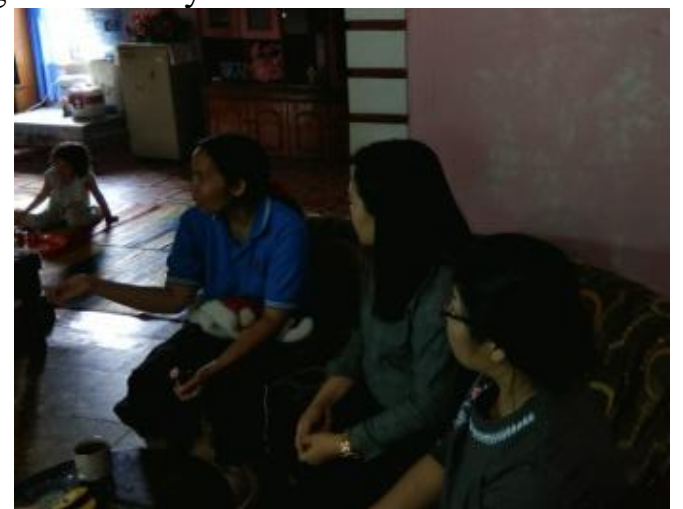

Gambar 1. Diskusi dengan Kepala Desa dan Ibu PKK

\section{2) Sosialisasi}

Pada tahapan ini, dilakukan sosialisasi kepada seluruh anggota Kelompok Tani Kopi dan memaparkan alasan dan tujuan Program Kemitraan Masyarakat dengan OHP.

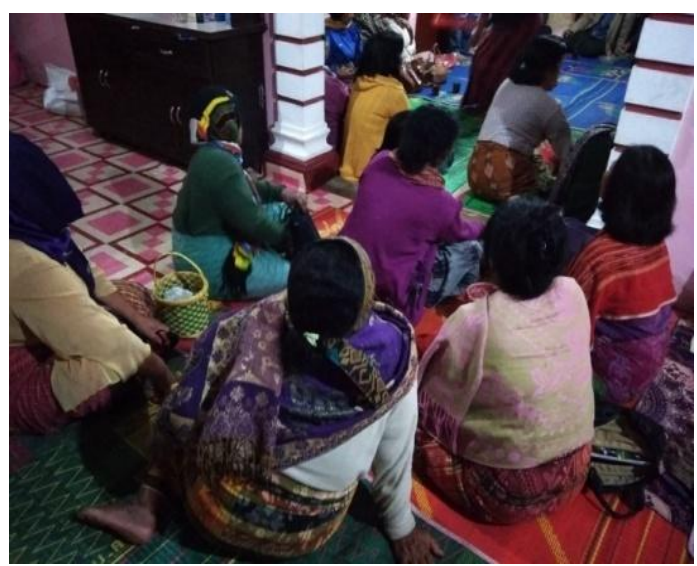

Gambar 2. Sosialisasi pada Anggota Kelompok Tani Kopi

\section{3) Pelaksanaan Kegiatan}


Pada tahapan ini, dilakukan penyerahan Mesin Huller kepada Kelompok Tani diterima oleh Kepala Desa Lingga.

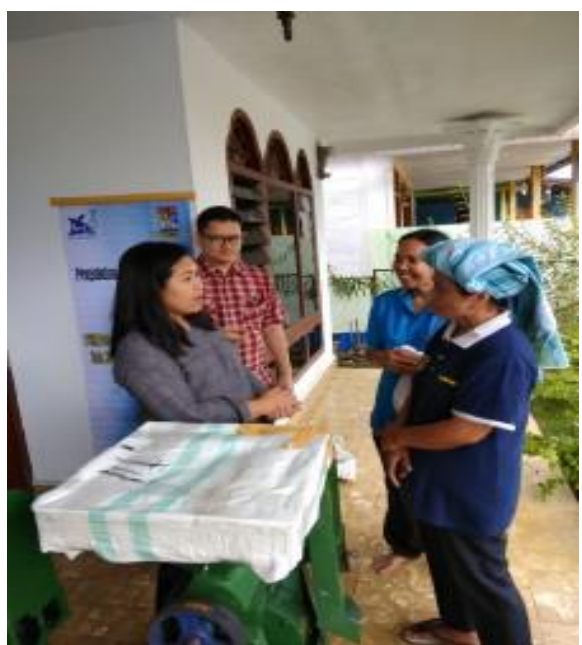

Gambar 3. Penjelasan Teknis pada Petani Kopi

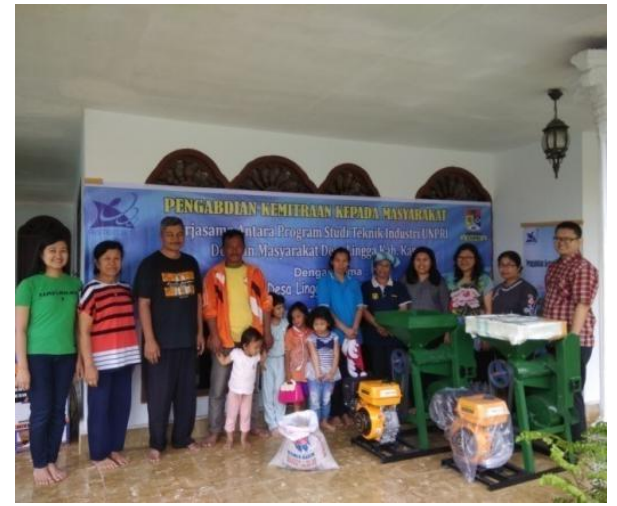

Gambar 4. Penyerahan Mesin Huller kepada Petani Kopi diwakili Kepala Desa

\section{4) Evaluasi Program}

Tahapan ini belum dilakukan karena masih mengumpulkan informasi mengenai dampak pelaksanaan, kelebihan, maupun kekurangan program.

\section{Rencana Keberlanjutan Program}

Merujuk pada hasil-hasil kegiatan PKM yang telah dilakukan, terutama kegiatan pelatihan mengenai pelatihan pemberdayaan petani kopi melalui proses pengolahan pasca panen kopi, maka diperlukan kegiatan pendampingan bagi keberlanjutan pengelolaan hasil pasca panen kopi, baik itu pra maupun pasca panen. Pendampingan dilakukan guna meningkatkan kesejahteraan petani kopi dalam mengelola hasil alam yaitu kopi hingga memiliki daya jual dan nilai ekonomis yang cukup tinggi, dari hasil kopi yang berkualitas.

\section{KESIMPULAN DAN SARAN \\ Kesimpulan}

Berdasarkan pemetaan dan assesment yang dilakukan mengenai kondisi masyarakat dan potensi sumberdaya yang ada. Sebelumnya, mitra tidak mampu mengolah pasca panen dengan tepat, salah satu kendala yang dirasakan oleh mitra adalah pengadaan alat dan teknologi baru dalam mengolah pasca panen yang kurang memadai. Selain itu mitra juga berikeinginan untuk dapat mengolah biji kopi menjadi kopi yang memiliki kualitas yang bagus dan menjadi khas oleh-oleh tanah karo. Aktivitas penanaman serta pengolahan kopi ini merupakan salah satu pengahasilan warga terutama warga di desa lingga, dan berdasarkan hasil assement awal diperoleh informasi bahwa selain memiliki potensi, terdapat juga beberapa masalah yang dihadapi oleh para petani kopi antara lain : belum memiliki sarana proses produksi pasca panen, alat/mesin untuk proses produksi masih kurang, kelompok belum memiliki modal yang cukup, dan anggota kelompok/kelompok kesulitan menjual langsung produk kopinya. Dengan memperhatikan kondisi tersebut, maka tim PKM berkesimpulan bahwa perlu adanya sebuah kegiatan yang mampu memberikan dampak postif terhadap peningkatan pemasaran atau produktifitas kopi.

Saran

Saran-saran untuk untuk program pengabdian masyarakat dapat dilanjutkan untuk tahap penggongsengan dan packaging sampai pemasaran berbasis online.

\section{UCAPAN TERIMA KASIH}

Penulis mengucapkan terima kasih kepada DRPM Kemenristekdikti yang telah memberikan bantuan hibah dana Pengabdian Kemitraan Masyarakat (PKM) kepada petani kopi di desa Lingga melalui kerjasama dengan Universitas Prima Indonesia, sehingga petani kopi memiliki alat kupas kulit tanduk (mesin huller) untuk meningkatkan perekonomian masyarakat dalam menjual buah kopi menjadi green bean.

\section{DAFTAR PUSTAKA}

AAK.2006. Budidaya Tanaman Kopi. Penerbit Kanisius yogyakarta.

Anonim,2012b. Pengolahan Kopi Cara Kering http:// www.starfarmagris.co.cc.html. Akses Tanggal 20 Oktober 2012. Makassar 
Asian Productivity Organization,. Handbook on Green Productivity, Tokyo: APO. http:/www.apo-tokyo.org/publications /wpcontent/uploads /sites/5/gp-hb_gp. pdf (2014).

Clarke, R. J. and Macrae, R,. Coffe Technology (Volume 2), Elsevier Applied Science, London and New York, (1987).

Ciptadi, W. dan Nasution, M.Z. 1985. Pengolahan Kopi. Fakultas Teknologi Institut Pertanian Bogor.

Rahardjo, Pudji. 2012. Panduan Budidaya dan Pengolahan Kopi Arabika dan Robusta. Penebar Swadaya. Jakarta.

Rusdianto AS. 2008. Peningkatan Kualitas Kopi Rakyat Dengan Penerapan HACCP. Jember.

Salwani. 2015. Kehidupan Sosial Ekonomi Petani Kopi Di Kecamatan Bintang Kabupaten Aceh Tengah 1974-2013.

Sri Najiyati dan Danarti., Budidaya Tanaman Kopi dan Penanganan Pasca Panen. Penebar Swadaya. Jakarta., (2004).

Sumanth, D.J.,. Productivity Engineering and Management, Mc Graw Hill Book Company, (1985).

Yovita, Yosefine. 2015. Pengawasan Mutu Buah Kopi Menjadi Kopi Bubuk Di PT Perkebunan Nusantara IX, Jambu-Semarang. Teknologi Pertanian. Universitas Katolik Soegijapranata Semarang. 